\title{
Understanding the surface and structural characteristics of tungsten oxide supported on tin oxide catalysts for the conversion of glycerol
}

\author{
M SRINIVAS $^{\mathrm{a}}$, G RAVEENDRA ${ }^{\mathrm{a}}$, G PARAMESWARAM ${ }^{\mathrm{a}}$, P S SAI PRASAD ${ }^{\mathrm{a}}$, \\ $\mathrm{S} \mathrm{LORIDANT}^{\mathrm{b}}$ and N LINGAIAH ${ }^{\mathrm{a}, *}$ \\ ${ }^{a}$ Catalysis Laboratory, I \& PC Division, CSIR-Indian Institute of Chemical Technology, \\ Hyderabad 500 007, India \\ b Institut de Recherchessur la Catalyse et l'Environnement de Lyon, IRCELYON, UMR 5256, CNRS, \\ Université Lyon I, 2 avenue Albert Einstein, 69626 Villeurbanne Cedex, France \\ e-mail: nakkalingaiah@iict.res.in
}

MS received 28 August 2014; revised 1 December 2014; accepted 28 December 2014

\begin{abstract}
Catalysts with varying $\mathrm{WO}_{3}$ content on $\mathrm{SnO}_{2}$ were prepared and characterized by X-ray diffraction, in situ Raman spectroscopy, X-ray photoelectron spectroscopy and temperature programmed desorption of $\mathrm{NH}_{3}$. In situ Raman analysis reveals the presence isolated monomers and polymeric species of $\mathrm{WO}_{3}$. These catalysts were evaluated for the conversion of glycerol into value added chemicals. Etherification of glycerol with tertiary butanol and preparation of glycerol carbonate from glycerol and urea are studied over these catalysts. The catalytic activity results suggest that the glycerol conversion and selectivity depends on the morphology of $\mathrm{WO}_{3}$ which in turn is related to its content in the catalyst. The catalysts with 5 wt. $\%$ of $\mathrm{WO}_{3}$ on $\mathrm{SnO}_{2}$ resulted in high dispersion with larger number of strong acidic sites. The selectivity in the glycerol etherification is related to the nature of the catalyst and reaction time. These catalysts also exhibited high activity for synthesis of glycerol carbonate. The effect of various reaction parameters was studied to optimize the reaction conditions. The catalysts also exhibited consistent activity upon reuse.
\end{abstract}

Keywords. Tungsten oxide; tin oxide; etherification; glycerol; tert-butanol; glycerol ethers

\section{Introduction}

Biodiesel, an eco-friendly biofuel is being chosen as an alternative to fossil fuels. Biodiesel has been produced in large quantities by transesterification of vegetable oils or animal fats. ${ }^{1}$ During the production of biodiesel approximately $10 \mathrm{wt} . \%$ of glycerol is obtained as byproduct. ${ }^{2}$ As the production of biodiesel is increasing with time, large quantities of glycerol have been accumulated in an already saturated market. This has led to a dramatic reduction on the economic value of glycerol as a raw material. This situation has fuelled a growing interest to look for new glycerol uses. ${ }^{3}$ Glycerol can be converted into several important chemicals ${ }^{4-8}$ such as 1,2-propanediol, 1, 3- propanediol, acrolein, glyceric acid, esters of glycerol and syngas, etc. The details about the glycerol conversion are comprehensively discussed in recent reviews. ${ }^{9-11}$ Etherification of glycerol with isobutylene or tert-butanol towards fuel oxygenates has been considered recently as a promising and economically viable method for the conversion of glycerol. Another important chemical derived from glycerol

*For correspondence is glycerol carbonate (GC), a highly value added product with many potential applications. ${ }^{12-16}$ Etherification of glycerol is generally facilitated by acid catalysts. Thus, acid catalysts such as sulfuric acid, p-toluenesulfonic acid, acidic ion exchange resins, wide pore zeolites, and acid-functionalized mesostructured silicas have been used for etherification of glycerol. ${ }^{17-27}$ Etherification of glycerol with tert-butanol produce a mixture of monotert-butyl glycerol ether (ME), di-tert-butyl glycerol ether (DE), and tri-tert-butyl glycerol ether (TE). Selective etherification of glycerol into monoalkyl glycerol ethers, which exhibit a wide spectrum of biological activities such as anti-inflammatory, anti-bacterial, antifungal, immunological stimulation and anti-tumour properties. ${ }^{28}$ Another important derivative of ME, dioxolanes, is also used as co-fuels for the diesel fraction. ${ }^{20}$

The main routes proposed for the synthesis of GC are: (i) reaction of glycerol with phosgene, ${ }^{29}$ (ii) transesterification of glycerol with dimethyl carbonate ${ }^{30-32}$ or ethylene carbonate, ${ }^{33}$ (iii) reaction of glycerol with urea, ${ }^{33-36}$ and (iv) carbonation of glycerol with carbon dioxide. ${ }^{37,38}$ Among the possible routes for the preparation of GC, the reaction of glycerol and carbon dioxide in the presence of a catalyst is the best approach. 
However, this method requires severe reaction conditions and the yield of glycerol carbonate is too low to be used for practical purpose. ${ }^{37,38}$ An alternative route for the GC synthesis is carbonation of glycerol with dimethyl carbonate or urea. Several authors studied the performance of solid catalysts including $\mathrm{ZnO},{ }^{39}$ zinc sulfate, ${ }^{40} \mathrm{ZnCl}_{2},{ }^{41} \gamma$-zirconium phosphate, ${ }^{42}$ $\mathrm{HTc}-\mathrm{Zn}$ derived from hydrotalcite, ${ }^{43} \mathrm{Co}_{3} \mathrm{O}_{4} / \mathrm{ZnO},{ }^{44}$ $\mathrm{Sm}$ exchanged heteropoly tungstate, ${ }^{45}$ gold supported ZSM-5, ${ }^{46}$ manganese sulfate, ${ }^{46}$ etc., for the preparation of GC from glycerol and urea. Although useful catalysts are reported, it is still a challenging task to develop new heterogeneous catalysts having a high performance under milder conditions.

Tin oxide $\left(\mathrm{SnO}_{2}\right)$ is one of the most attractive functional materials because of potential applications particularly as a catalyst and also as a carrier for supported catalysts. Furuta et al. ${ }^{47}$ compared the activities of sulfated zirconia and sulfated tin oxide for etherification reaction of methanol and reported that sulfated tin oxide is active due its high acidity. However, in order to promote the thermal stability and catalytic property of the pure tin oxide, using high valence cation of oxide was previously reported. ${ }^{48,49}$ Thus, it is of interest to study the novelties of $\mathrm{WO}_{3}$ supported $\mathrm{SnO}_{2}$ catalysts for the conversion of glycerol.

In the present study, a series of $\mathrm{WO}_{3}$ supported on $\mathrm{SnO}_{2}$ catalysts were prepared and studied for selective etherification of glycerol with tert-butanol and synthesis of glycerol carbonate from glycerol and urea. Understanding the surface and structural properties of the catalysts towards glycerol etherification and optimization of reaction parameters was also the aim of the present study.

\section{Experimental}

All the chemicals used in this study were of analytical grade. Glycerol (99\%) was obtained from Fisher Scientific. tert-butanol (99\%), ammonium meta-tungstate $(99.5 \%)$ and tin oxide $(99.9 \%)$ were obtained from Sigma-Aldrich. A series of $\mathrm{WO}_{3} / \mathrm{SnO}_{2}$ catalysts were prepared by impregnation method. In a typical method required amount of ammonium meta-tungstate hydrate $\left[\left(\mathrm{NH}_{4}\right)_{6} \mathrm{H}_{2} \mathrm{~W}_{12} \mathrm{O}_{40} \cdot \mathrm{nH}_{2} \mathrm{O}\right]$ was dissolved in distilled water and this solution was added to calculated amount of tin oxide with stirring. The solution was stirred for a period of $2 \mathrm{~h}$ and the excess water was removed on a hot plate. The dried sample was kept overnight for further drying at $393 \mathrm{~K}$. The final catalyst was obtained by calcination at $773 \mathrm{~K}$ for $4 \mathrm{~h}$. The amount of $\mathrm{WO}_{3}$ on $\mathrm{SnO}_{2}$ is varied from 2 to $10 \mathrm{wt}$. \%. The catalysts were designated as $\mathrm{x} \% \mathrm{WS}$, where $\mathrm{x}$ indicates the weight percentage of $\mathrm{WO}_{3}$ on $\mathrm{SnO}_{2}$ and $\mathrm{W}$ and $\mathrm{S}$ stands for $\mathrm{WO}_{3}$ and $\mathrm{SnO}_{2}$.

\subsection{Characterization of the catalysts}

X-ray diffraction (XRD) patterns of the catalysts were recorded on a RigakuMiniflex diffractometer using $\mathrm{CuK} \alpha$ radiation $\left(1.5406 \mathrm{~A}^{\circ}\right)$ at $40 \mathrm{kV}$ and $30 \mathrm{~mA}$. The measurements were obtained in steps of $0.045^{\circ}$ with an account time of $0.5 \mathrm{~s}$ and in the $2 \theta$ range of $10-80^{\circ}$. Confocal micro-Raman spectra were recorded with a LabRam HR Raman spectrometer (Horiba-JobinYvon) equipped with BXFM confocal microscope, interference and Notch filters and Charge-Coupled Device detector. The exciting lines at $514.5 \mathrm{~nm}$ of a $2018 \mathrm{RM}$ $\mathrm{Ar}^{+}-\mathrm{Kr}^{+}$laser (Spectra Physics) were focused using $\times 50$ long working distance objective and the diffused light was dispersed with grating of 1800 lines $^{-1} . \mathrm{mm}^{-1}$ leading to spectral resolution of ca $0.5 \mathrm{~cm}^{-1}$. In situ Raman spectra were recorded between RT and $873 \mathrm{~K}$ under air using THMS600 cell (Linkam). The homogeneity of the catalysts at the micrometer scale was controlled achieving spectra on different points.

Temperature programmed desorption (TPD) of ammonia was carried out on a laboratory-built apparatus equipped with a gas chromatograph using a TCD detector. In typical experiments about $0.1 \mathrm{~g}$ of the oven dried sample was taken in a quartz tube. Prior to TPD studies, the catalyst sample was treated at $573 \mathrm{~K}$ for 1 $\mathrm{h}$ by passing pure He gas $(99.995 \%, 50 \mathrm{~mL} / \mathrm{min})$. After pre-treatment, the sample was saturated with anhydrous ammonia $\left(10 \% \mathrm{NH}_{3}\right.$ balance $\left.\mathrm{He}\right)$ at $373 \mathrm{~K}$ with a flow rate of $50 \mathrm{~mL} / \mathrm{min}$ for $1 \mathrm{~h}$ and was subsequently flushed with $\mathrm{He}$ at the same temperature to remove physisorbed ammonia. The process was continued until a stabilized base line was obtained in the gas chromatograph. Then the TPD analysis was carried out from ambient temperature to $973 \mathrm{~K}$ at a heating rate of $10 \mathrm{~K} / \mathrm{min}$. The amount of $\mathrm{NH}_{3}$ evolved was calculated from the peak area of the already calibrated TCD signal.

X-ray photo electron spectroscopy (XPS) measurements were conducted on a KRATOS AXIS 165 with a DUAL anode ( $\mathrm{Mg}$ and $\mathrm{Al}$ ) apparatus using $\mathrm{Mg} \mathrm{K}$ anode. The non-monochromatized AlK $\alpha$ X-ray source $(\mathrm{h} v=1486.6 \mathrm{eV})$ was operated at $12.5 \mathrm{kV}$ and $16 \mathrm{~mA}$. Before acquisition of the data, each sample was outgassed for about $3 \mathrm{~h}$ at $373 \mathrm{~K}$ under vacuum of 1.0 $\times 10^{-7}$ Torr to minimize surface contamination. The XPS instrument was calibrated using Au as standard. For energy calibration, the carbon 1s photoelectron line was used. The carbon $1 \mathrm{~s}$ binding energy was taken as $285 \mathrm{eV}$. Charge neutralization of $2 \mathrm{eV}$ was used to 


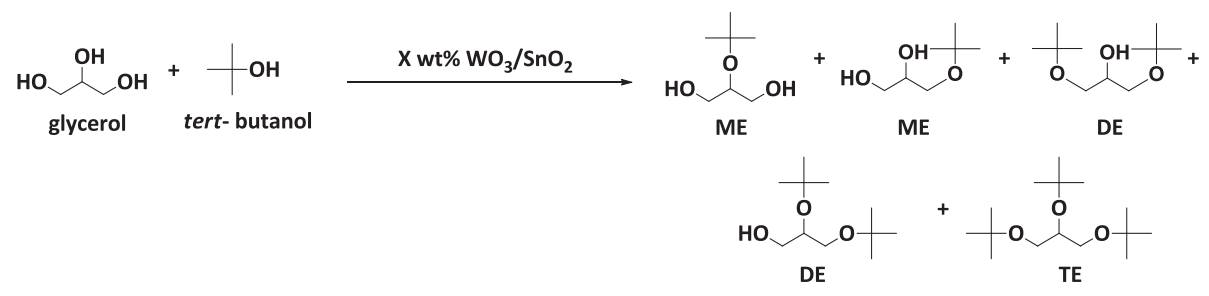

Scheme 1. Etherification of glycerol with tert-butanol.

balance the charge up of the sample. The spectra were decomposed into individual components using Sun Solaris Vision-2 curve resolver. The location and the full width at half maximum (FWHM) value for the species were first determined using the spectrum of a pure sample. Symmetric Gaussian functions were used in all cases. Binding energies for identical samples were, in general, reproducible within $\pm 0.1 \mathrm{eV}$.

\subsection{Reaction procedures}

2.2a Etherification of glycerol with tert-butanol: Etherification of glycerol with tert-butanol (scheme 1) was carried out in a $100 \mathrm{~mL}$ haste alloy PARR autoclave. Required quantities of glycerol, tert-butanol and catalyst were introduced in to the autoclave and purged three times with $\mathrm{N}_{2}$. After the third purge, the reactor was heated to desired reaction temperature. During the course of reaction, pressure was developed autogenously. After the reaction, the gas phase products were collected in a gasbag and the liquid phase products were separated from the catalyst by filtration. The liquid samples were analyzed by using a gas chromatograph (Shimadzu, 2010) equipped with flame ionization detector (FID) using INNO-WAX capillary column (diameter: $0.25 \mathrm{~mm}$, length $30 \mathrm{~m}$ ). The products were confirmed by GC-MS (Shimadzu, GCMS-QP2010) analysis. The gas products were analyzed by using a gas chromatograph (Porapak Q column) equipped with a thermal conductivity detector (TCD). The products identified during etherification of glycerol were mono tert-butyl glycerol ethers (ME), di tert-butyl glycerol ethers (DE), and tri tert-butyl glycerol ethers (TE).

2.2b Carbonylation of glycerol with urea: Carbonylation of glycerol with urea (scheme 2) was performed in a $25 \mathrm{~mL}$ two neck round-bottom (RB) flask under reduced pressures. In a typical experiment glycerol (2 $\mathrm{g})$, urea $(1.306 \mathrm{~g})$ and catalysts $(0.2 \mathrm{~g})$ were taken in the round bottom flask and heated in an oil bath at $413 \mathrm{~K}$ with constant stirring. One neck of the RB flask was connected to vacuum line. Reaction was run under a reduced pressure in order to remove the ammonia formed during the reaction. After completion of reaction or stipulated time, methanol was added and the catalyst was separated by filtration. The products were identified by GC-MS (Shimadzu, GCMS-QP2010S) analysis. The products were analyzed with a Shimadzu, 2010 gas chromatograph equipped with INNO-WAX capillary column (diameter: $0.25 \mathrm{~mm}$, length $30 \mathrm{~m}$ ) and flame ionization detector.

Conversion of the glycerol and selectivity was calculated on the basis of the following equation with respect to glycerol:

Conversion $(\%)=\frac{\text { Number of moles of glycerol reacted }}{\text { Total number of moles of glycerol taken }} \times 100$

Selectivity $(\%)=\frac{\text { Number of moles desired product }}{\text { Total number of moles of all products }} \times 100$

\section{Results and Discussion}

\subsection{X-ray diffraction of catalyst}

XRD patterns of the catalysts are shown in figure 1 . The patterns of the $\mathrm{SnO}_{2}$ support and $\mathrm{WO}_{3}$ were included for the sake of comparison. The XRD pattern were quite consistent with the tetragonal cassiterite (rutile) (JCPDS No. 41-1445) structure of $\mathrm{SnO}_{2},{ }^{38}$ and no characteristic diffraction peaks of the impurities and other compounds were found with the lower loadings of

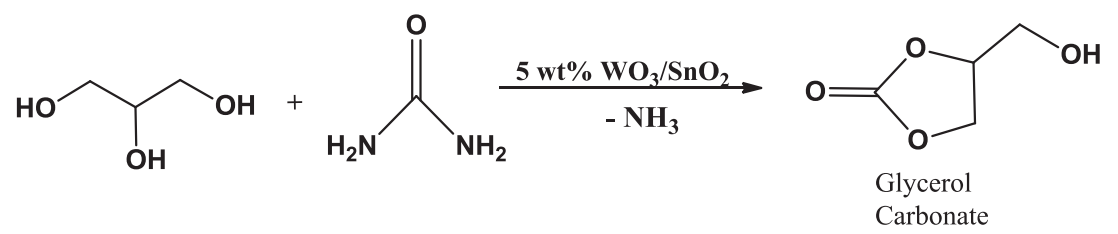

Scheme 2. Reaction scheme for the carbonylation of glycerol with urea. 


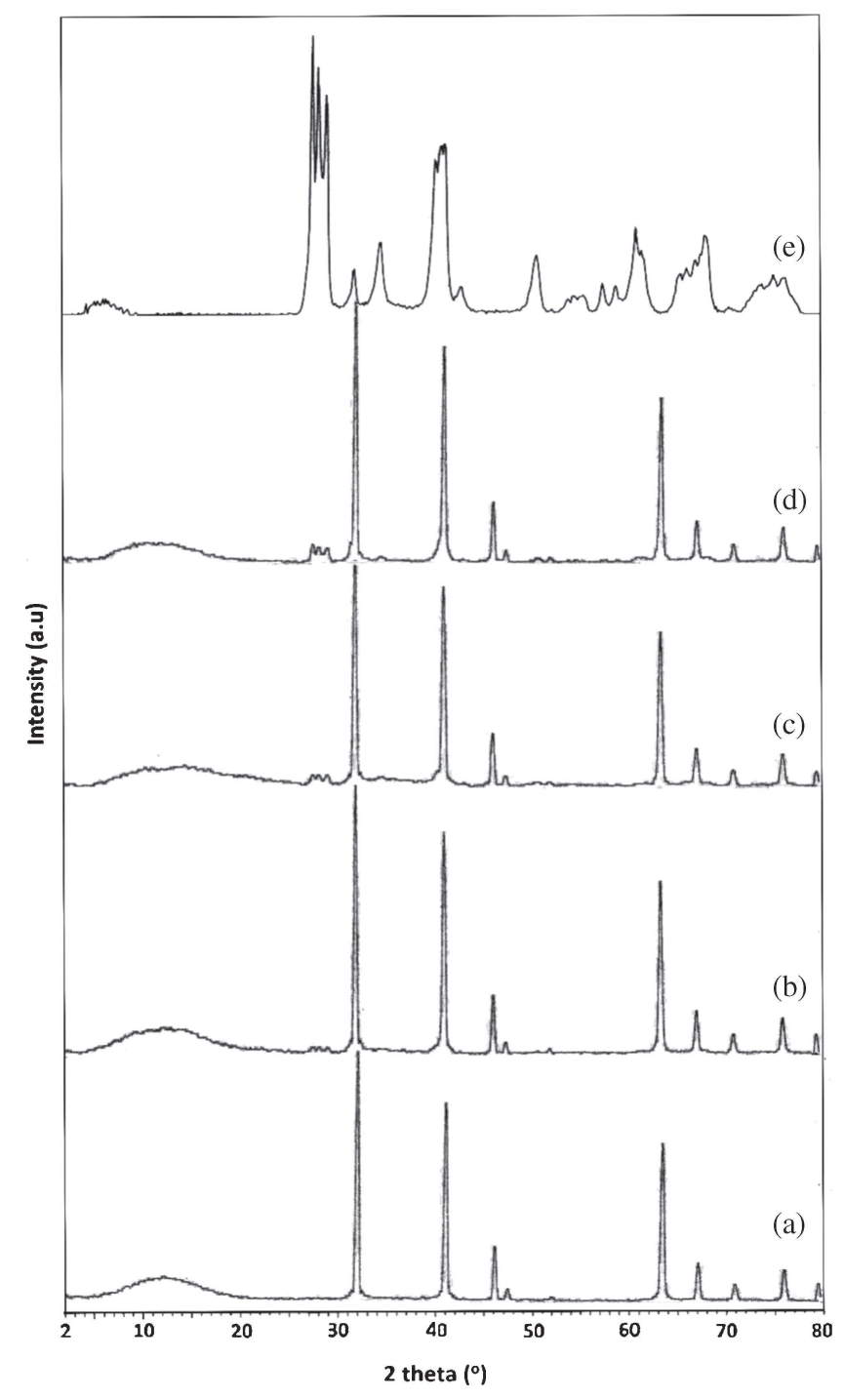

Figure 1. XRD patterns of $\mathrm{x} \% \mathrm{WO}_{3} / \mathrm{SnO}_{2}$ catalysts (a) 2WS (b) $5 \mathrm{WS}$, (c) $7.5 \mathrm{WS}$, (d) $10 \mathrm{WS}$ and (e) $\mathrm{WO}_{3}$.

$\mathrm{WO}_{3}$, this implies that the $\mathrm{WO}_{3}(\leq 5 \mathrm{wt} . \%)$ might exist as an amorphous oxide on the $\mathrm{SnO}_{2}$, and is considered to act as a barrier against development of grain boundaries of $\mathrm{SnO}_{2}$ and effectively prevent the grain growth. ${ }^{50}$ When the composition of the $\mathrm{WO}_{3}$ in the catalyst was higher than $5 \mathrm{wt} . \%$, the diffraction peaks of monoclinic $\mathrm{WO}_{3}$ crystals were observed in the XRD patterns. ${ }^{51,52}$ The crystallization of $\mathrm{WO}_{3}$ was accompanied by a loss of specific surface area.

\subsection{In situ Raman spectra}

In situ Raman spectra were achieved during calcination up to $873 \mathrm{~K}$ under air of freshly prepared 2, 5 and 7.5WS catalysts. Raman spectra of these catalysts were measured with stepwise increase in temperature. The most relevant spectra of 2, 5 and $7.5 \mathrm{WS}$ catalysts are shown in figures 2(a), 2(b) and 2(c) respectively.
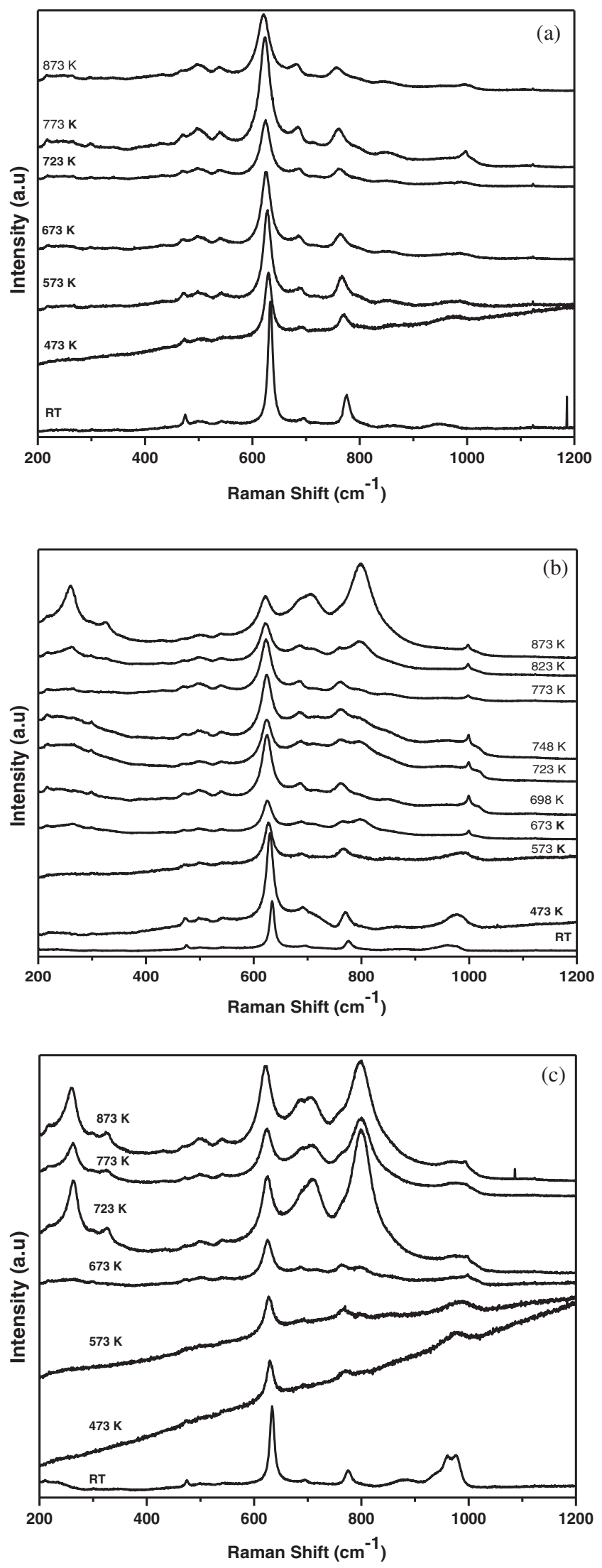

Figure 2. In situ Raman spectra of $\mathrm{x} \%$ WS catalysts (a) 2WS, (b) 5WS and (c) 7.5WS 
The 2WS catalyst showed predominantly the bands at 475,629 and $768 \mathrm{~cm}^{-1}$ related to $\mathrm{SnO}_{2}$ cassiterite crystalline phase. The band at $685 \mathrm{~cm}^{-1}$ was assigned to an $\mathrm{A}_{2 \mathrm{u}}$ (LO) mode that becomes weakly Raman-active because of structural distortions induced by disorder. ${ }^{53,54}$ Additionally, the broad bands at 850 and $985 \mathrm{~cm}^{-1}$ were respectively attributed to stretching vibrations of $\mathrm{W}-\mathrm{O}-\mathrm{W}$ bridging bonds $(v(\mathrm{~W}-\mathrm{O}-\mathrm{W}))$ and to stretching vibrations of terminal $\mathrm{W}=\mathrm{O}$ bonds $(v(\mathrm{~W}=\mathrm{O}))$ of hydrated polymeric by analogy with the spectra of such species supported over other oxides. ${ }^{55,56}$ The bands near 270, 715 and $805 \mathrm{~cm}^{-1}$ related to crystalline $\alpha-\mathrm{WO}_{3}{ }^{57,58}$ were absent even after the catalyst exposed to $873 \mathrm{~K}$. This suggests that the $\mathrm{WO}_{3}$ was well dispersed on $\mathrm{SnO}_{2}$. Upon raising the temperature up to $873 \mathrm{~K}$, the $v(\mathrm{~W}=\mathrm{O})$ vibrations were shifted to 998 $\mathrm{cm}^{-1}$ and became thinner because of dehydration ${ }^{55-57}$ whereas the $v(\mathrm{~W}-\mathrm{O}-\mathrm{W})$ vibrations around $850 \mathrm{~cm}^{-1}$ remained almost unchanged. The Raman spectra of $5 \mathrm{WS}$ catalysts showed similar spectra as that of $2 \mathrm{WS}$ at low calcination temperatures. Above $673 \mathrm{~K}$, a thin $(\mathrm{W}=\mathrm{O})$ band at $999 \mathrm{~cm}^{-1}$ and a broad one at $1017 \mathrm{~cm}^{-1}$ were distinguished and ascribed to isolated monomers and polymeric species respectively. ${ }^{56,59}$ Broad bands near 715 and $805 \mathrm{~cm}^{-1}$ that remained weak from 673 to $773 \mathrm{~K}$ were additionally observed and were ascribed to $\mathrm{WO}_{3}$ nano particles. The micro-Raman spectra obtained on different areas of the sample revealed good homogeneity at the micrometre scale which suggested that these nano particles were well dispersed on $\mathrm{SnO}_{2}$. Above $773 \mathrm{~K}$, the bands of crystalline $\alpha-\mathrm{WO}_{3}$ became intense revealing crystalline growth and the microRaman spectra achieved on different areas showed the heterogeneities at the micro meter scale. The Raman spectrum of uncalcined $7.5 \mathrm{WS}$ catalyst was different from the spectra of 2 and 5WS catalysts. Indeed, in addition to the bands of $\mathrm{SnO}_{2}$, some bands were observed at 975,960 and $935 \mathrm{~cm}^{-1}$ and attributed to $\left(\mathrm{NH}_{4}\right)_{6} \mathrm{H}_{2} \mathrm{~W}_{12} \mathrm{O}_{40}$ salt $^{54}$ that re-precipitated during drying because of the high concentration of the impregnation solution. Additionally, formation of crystalline $\mathrm{WO}_{3}$ was evidenced above only at $673 \mathrm{~K}$. This feature was related to the higher $\mathrm{WO}_{3}$ surface density at which the monolayer coverage was reached. These results indicated that the maximal coverage of $\mathrm{WO}_{3}$ clusters on $\mathrm{SnO}_{2}$ was obtained for the 5WS catalyst after calcination at $773 \mathrm{~K}$ which is in agreement with XRD observations.

\subsection{TPD of ammonia}

Ammonia adsorption-desorption technique permits to determine the strength of acid sites present on catalyst

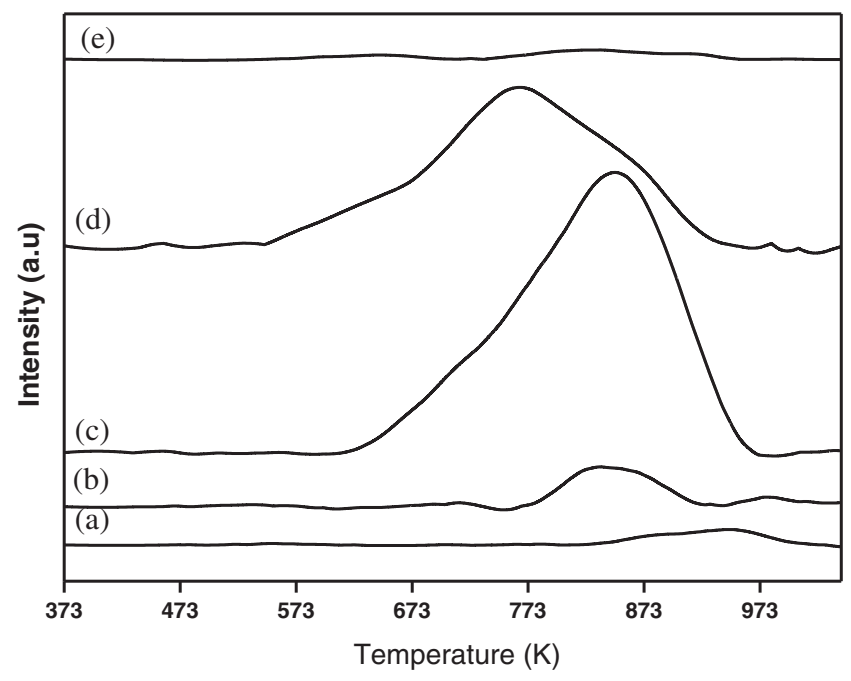

Figure 3. Temperature programmed desorption profiles of ammonia on WS catalysts (a) $\mathrm{SnO}_{2}$, (b) $2 \mathrm{WS}$, (C) $5 \mathrm{WS}$, (d) 7.5WS, and (e) 10WS

surface, together with total acidity. The TPD profiles of the catalysts are shown in figure 3. The TPD profile of $\mathrm{SnO}_{2}$ sample was also included for sake of comparison. The catalysts with low $\mathrm{WO}_{3}(2 \mathrm{WS})$ content did not show any appreciable acidity generated by the presence of molecular tungsten oxide. However, with further increase in $\mathrm{WO}_{3}$ content, a drastic enhancement in the acidity was noticed. This catalyst showed $\mathrm{NH}_{3}$ desorption peaks centred between $743 \mathrm{~K}$ and $973 \mathrm{~K}$. The high temperature desorption of $\mathrm{NH}_{3}$ corresponds to moderate to strong acidic sites of the catalysts originating due to well-dispersed $\mathrm{WO}_{3}$ clusters. After further increasing the $\mathrm{WO}_{3}$ content, the high temperature desorption peak shifted to low temperature. The catalysts with high $\mathrm{WO}_{3}$ amount showed only one desorption peak at high temperature that was associated to the crystalline $\mathrm{WO}_{3}$ present on $\mathrm{SnO}_{2}$ as revealed by XRD patterns and Raman spectra. The acidity values of these catalysts are presented in table 1 . As a whole the TPD results suggests the presence of well-dispersed $\mathrm{WO}_{3}$ clusters on $\mathrm{SnO}_{2}$ leads to generation of maximum number moderate to strong acidic sites.

Table 1. Acidity and surface area of the catalysts.

S. No. Reaction time (min) $\mathrm{S}_{\mathrm{BET}}\left(\mathrm{m}^{2} / \mathrm{g}\right)$ Acidity $(\mathrm{mmol} / \mathrm{g})$

\begin{tabular}{lccc}
\hline 1 & $\mathrm{SnO}_{2}$ & 11.6 & 0.064 \\
2. & $2 \mathrm{WS}$ & 10.5 & 0.210 \\
3. & $5 \mathrm{WS}$ & 9.8 & 0.271 \\
4. & $7.5 \mathrm{WS}$ & 8.4 & 0.158 \\
5. & $10 \mathrm{WS}$ & 7.1 & 0.126 \\
6. & $\mathrm{WO}_{3}$ & 6.0 & 0.135 \\
\hline
\end{tabular}




\subsection{Activity measurements of the catalysts}

3.4a Etherification of glycerol: The etherification of glycerol was carried over $\mathrm{WO}_{3} / \mathrm{SnO}_{2}$ catalysts and the results are provided in figure 4 . The etherification of glycerol over these catalysts leads to the formation of mainly mono tertiary butyl glycerol ether with selectivities reaching ca $88 \%$. A small amount of both di and tri tertiary butyl glycerol ethers are also formed. There was no much variation in the selectivities of the catalysts with change in $\mathrm{WO}_{3}$ loading. Additionally, the figure clearly show that the rate of the reaction increased with increase in the $\mathrm{WO}_{3}$ loading up to $5 \mathrm{wt} . \%$ and thereafter decreased. The optimum activity obtained for the catalyst with $5 \% \mathrm{WO}_{3}$ on $\mathrm{SnO}_{2}$. The catalytic reaction rate $\mathrm{V}_{\mathrm{t}}$ can be calculated by the following equation:

$$
\text { Rate of the reaction, } V_{\mathrm{t}}=\frac{m_{s}}{t M_{c a t}}
$$

Where $\mathrm{v}_{t}$ is the catalytic reaction rate, $m_{s}$ is the moles of the glycerol converted within the reaction time of $t$, and $M_{\text {cat }}$ is the mass of a catalyst.

In order to investigate the variation in activity and selectivity of the 5WS catalyst with reaction time, data were collected at different reaction times and the results are shown in table 2 . The glycerol conversion increased with reaction time from 30 to $60 \mathrm{~min}$ and thereafter no much variation was noticed. The conversion of glycerol was high even at 30 min suggesting the high activity of the catalyst. The overall selectivity to ME is more. The formation of higher tertiary butyl glycerol ether (HE) was noticed at longer reaction times. Initially, the selectivity towards mono ether was high and

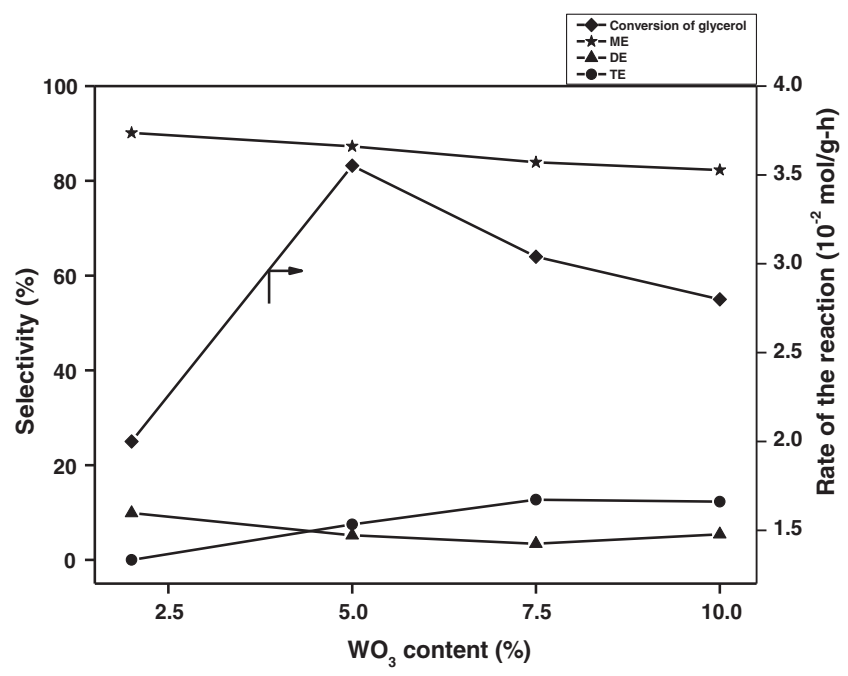

Figure 4. Catalytic performance of WS catalysts for the synthesis of mono tert-butyl glycerol ether. Reaction conditions: glycerol (1.84 g), tert-butanol (13.34 g), catalyst weight $(0.5 \mathrm{~g})$, reaction temperature $(393 \mathrm{~K})$, reaction time $(1 \mathrm{~h})$.
Table 2. Comparison of glycerol conversion and product selectivity with reaction time.

\begin{tabular}{lcccc}
\hline \multirow{2}{*}{ Reaction Time (Min) } & \multirow{2}{*}{ Conversion (\%) } & \multicolumn{3}{c}{ Selectivity (\%) } \\
\cline { 3 - 5 } & & ME & DE & TE \\
\hline 30 & 68.6 & 94.5 & 3.8 & 1.7 \\
60 & 88.8 & 87.8 & 7.5 & 4.7 \\
90 & 90 & 87.1 & 6.6 & 6.3 \\
120 & 82.2 & 85.8 & 7.7 & 6.5 \\
\hline
\end{tabular}

Reaction conditions: glycerol (1.84 g), tert-butanol (13.34 g), catalyst weight $(0.5 \mathrm{~g})$, reaction temperature $(393 \mathrm{~K})$.

as the reaction prolonged, the selectivity towards di and tri ethers increased marginally at the expense of mono ether. Overall the catalyst is highly active and selective towards ME within short reaction time.

The activity of the catalysts can be explained based on their surface and structural characteristics. The XRD patterns suggest the presence of amorphous $\mathrm{WO}_{3}$ phase for the catalysts with low $\mathrm{WO}_{3}$ content. The formation of $\mathrm{WO}_{3}$ crystallites were observed for the catalysts with $>7.5 \mathrm{WO}_{3}$. The high activity of $5 \mathrm{WS}$ catalysts might be due to the presence of well-dispersed $\mathrm{WO}_{3}$ clusters on $\mathrm{SnO}_{2}$ surface. This catalyst also showed maximum acidity with high number of moderate and strong acidic sites. Similar behaviour is reported for $\mathrm{WO}_{3}$ based catalysts where the presence of amorphous $\mathrm{WO}_{3}$ on $\mathrm{ZrO}_{2}$ resulted in generation of strong acidic sites and thereby high esterification activity. ${ }^{60}$ The acidity of the catalysts decreased with the presence of crystallites of $\mathrm{WO}_{3}$.

The 5WS catalyst showed the presence of more number of acidic sites (table 1) which are responsible for high activity figure 5 . Ball et al. ${ }^{61}$ reported that the reaction between alcohols with urea to form alkyl

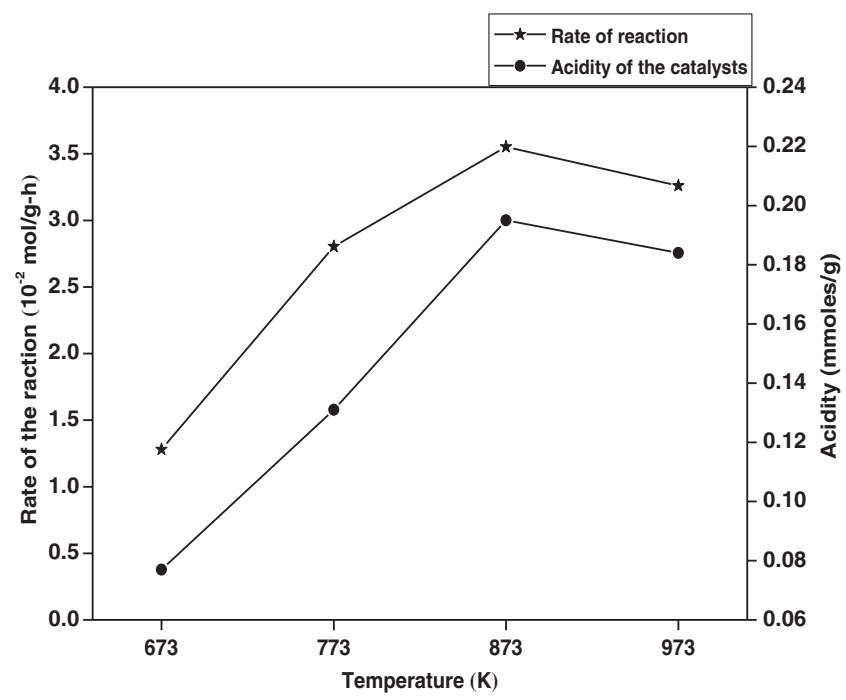

Figure 5. Comparison for acidity of the catalysts with the rate of reaction. 
carbonates can be improved using an adequate combination of a weak Lewis acid and Lewis base. In the present case also, moderate Lewis acidic sites are generated with the impregnation of $\mathrm{WO}_{3}$ over $\mathrm{SnO}_{2}$. The catalysts which possess most of these sites showed maximum activity. The high acidity for the catalyst was generated from Lewis acid sites which can be observed from TPD of $\mathrm{NH}_{3}$ (figure 3). In order to understand further how the surface and structural characteristics are playing a role in glycerol etherification, the most active catalysts was subjected to calcination at different temperatures.

3.4b Effect of catalyst calcination temperature: The catalyst 5WS was subjected to different calcination temperatures in the range of 673 to $973 \mathrm{~K}$ and tested for their etherification activity. The corresponding results are shown in table 3. The conversion of glycerol increased with increase in calcination temperature from 673 to $773 \mathrm{~K}$ and decreased thereafter. In order to find the variation in activity with change in calcination temperature, these catalysts were further characterized. The acidity of the catalysts was measured from TPD of ammonia. The acidity of the catalysts decreased gradually after calcination of the catalyst above $773 \mathrm{~K}$. The acidity of these catalysts and their etherification of glycerol activity were correlated and the relevant plot is shown in figure 5 . The results indicate that there exists a linear relation between acidity of the catalysts with that of its glycerol etherification activity. Further, the in situ Raman analysis supports the activity profiles of the catalysts calcined at different temperatures. The catalysts when exposed to temperature above $773 \mathrm{~K}$ showed the bands related to crystalline $\alpha-\mathrm{WO}_{3}$ phase. The growth in the crystallites of $\mathrm{WO}_{3}$ resulted in the heterogeneity on the catalysts surface at micrometer scale. This might be a reason for low activity of the catalyst calcined above $773 \mathrm{~K}$. The conversion and selectivity during glycerol etherification not only depends on the nature

Table 3. Comparison of glycerol conversion and product selectivity with $5 \mathrm{WS}$ catalyst calcined at different temperature.

\begin{tabular}{lcccc}
\hline Temperature (K) & Conversion (\%) & \multicolumn{3}{c}{ Selectivity $(\%)$} \\
\cline { 2 - 5 } & & ME & DE & TE \\
\hline 673 & 70.1 & 93.3 & 4.3 & 2.3 \\
773 & 88.8 & 87.8 & 7.5 & 4.7 \\
873 & 81.5 & 92.6 & 4.3 & 2.8 \\
973 & 77.1 & 90.2 & 6.5 & 3.3 \\
\hline
\end{tabular}

Reaction conditions: glycerol (1.84 g), tert-butanol (13.34 g), catalyst weight $(0.5 \mathrm{~g})$, reaction temperature $(393 \mathrm{~K})$, reaction time $(1 \mathrm{~h})$.

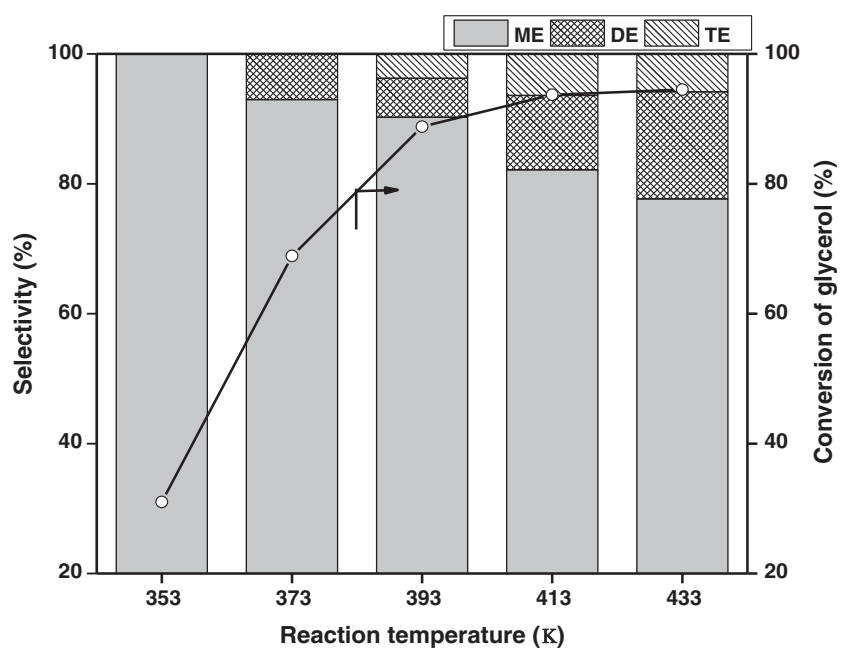

Figure 6. Comparison of glycerol conversion and product selectivity with reaction temperature. Reaction conditions: glycerol (1.84 g), tert-butanol (13.34 g), catalyst weight $(0.5 \mathrm{~g})$, reaction time $(1 \mathrm{~h})$.

of the catalyst but also on reaction parameters. The influence of different reaction parameters such as reaction temperature, catalyst weight and glycerol to tertbutanol molar ratio were also studied.

3.4c Effect of reaction temperature: The etherification of glycerol was carried out at different temperatures ranging from 353 to $433 \mathrm{~K}$ and the results are presented in figure 6 . The percentage conversion of glycerol increased with increase in reaction temperature and attained an equilibrium at a reaction temperature of $413 \mathrm{~K}$. The selectivity also varied with increase in reaction temperature. The formation of di and tri-tertbutyl glycerol ethers was increased gradually with further increase in reaction temperature. This is mainly due to the attainment of maximum conversion of glycerol. The successive etherification of ME is taking place at high reaction temperature, as there was less availability of glycerol. The optimum reaction temperature is $393 \mathrm{~K}$ as at this temperature maximum conversion and high selectivity towards ME was obtained.

\section{4d Effect of glycerol to tert-butanol molar ratio:} Figure 7 shows the effect of glycerol to tert-butanol molar ratio on the etherification of glycerol. The conversion of glycerol increased from 53.5 to $84 \%$ with the increase in the molar ratio of glycerol to tert-butanol from 1:3 and 1:6. Further increase in the molar does not lead to appreciable increase in glycerol conversion. A marginal decrease in glycerol conversion was observed at a very high molar ratio of glycerol to tert-butanol of $1: 12$. The observed decrease in catalytic activity at high molar ratio might be due to the saturation of catalyst 


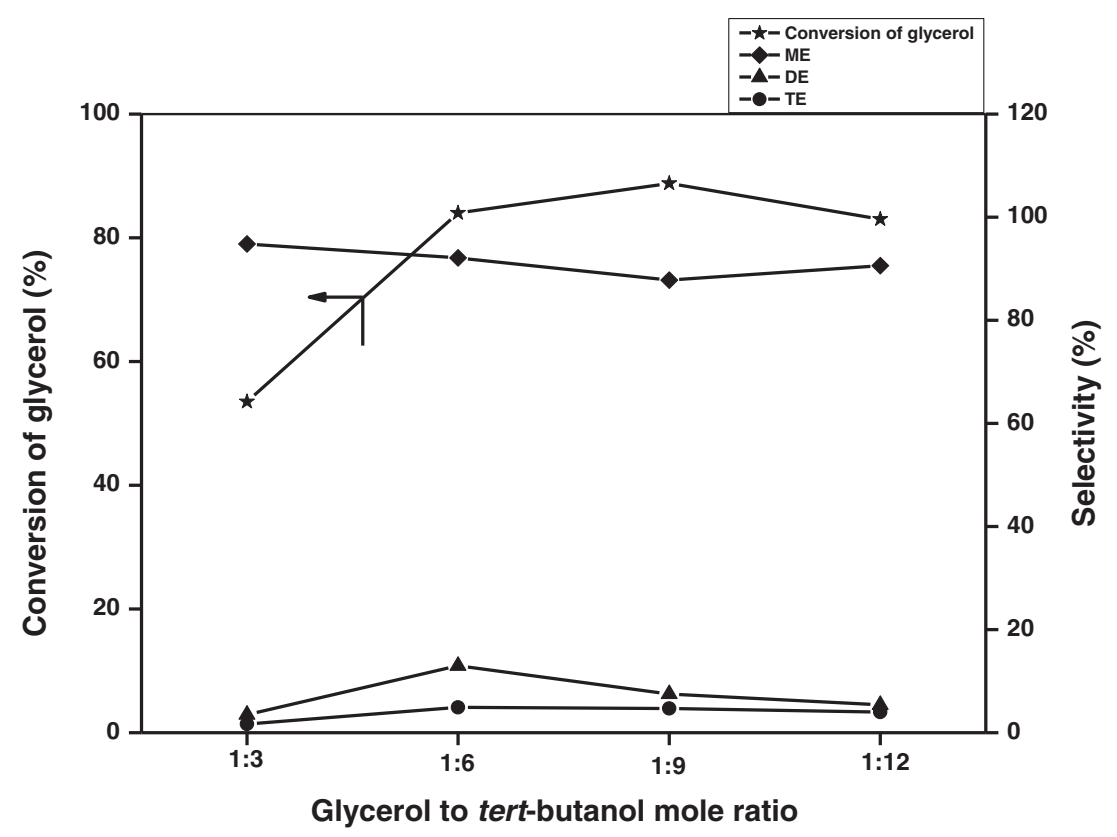

Figure 7. Comparison of glycerol conversion and product selectivity with mole ratio. Reaction conditions: catalyst weight $(0.5 \mathrm{~g})$, reaction temperature $(393 \mathrm{~K})$, reaction time $(1 \mathrm{~h})$.

surface with tert-butanol by blocking the acidic centres. Thus, one can say that there is a competitive adsorption by tert-butanol on the acid sites with glycerol, which reduces the efficiency of the catalyst. A glycerol to tertbutanol molar ratio of about 1:6 to 1:9 was found to be optimum for the selective synthesis of mono ethers with high glycerol conversion. 3.4e Effect of catalyst loading: Catalyst loading is an important parameter that needs to be optimized to increase the glycerol conversion. Figure 8 shows the effect of catalyst amount on glycerol conversion. From the figure, it can be seen that the glycerol conversion increased with increase in catalyst amount and reached maximum at a catalysts amount of $21.4 \%$.

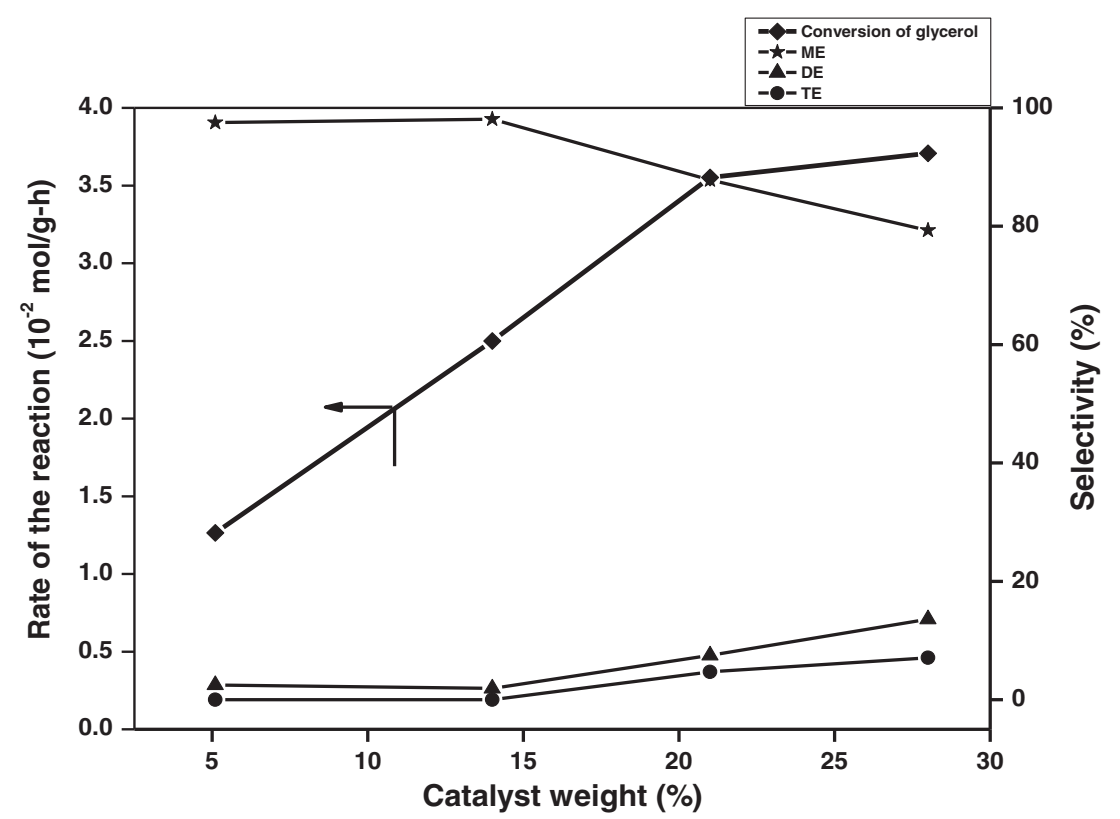

Figure 8. Comparison of glycerol conversion and product selectivity with catalyst loading. Reaction conditions: glycerol (1.84 g), tert-butanol (13.34 g), reaction temperature $(393 \mathrm{~K})$, reaction time $(1 \mathrm{~h})$. 
Thereafter, further increase in catalyst loading no substantial increase in glycerol conversion was observed. However, as more catalyst is introduced into the reaction mixture, it provides an external contact surface area that facilitates further etherification of mono-tert-butyl glycerol ether. As more ME is produced, it eventually acted as co-solvent and subsequently, the reaction rate is being controlled by the diffusion of the reactants to the active sites, instead of catalyst loading. Once, increasing the dosage of catalyst in the reaction mixture had no significant effect on the glycerol conversion. However, with increase in the catalyst amount the selectivity towards DE and TE have been increased. This is mainly because there was less availability of glycerol, as it is

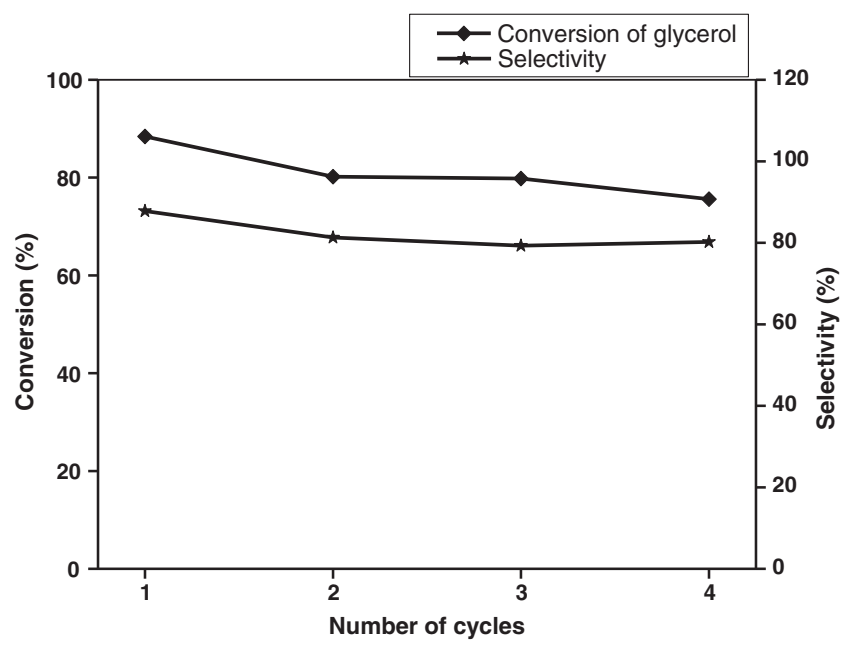

Figure 9. Reusability of $5 \mathrm{wt} \% \mathrm{WO}_{3} / \mathrm{SnO}_{2}$ catalyst for etherification of glycerol. Reaction conditions: glycerol (1.84 $\mathrm{g})$, tert-butanol (13.34 g), catalyst weight (0.5 g), reaction temperature $(393 \mathrm{~K})$, reaction time $(1 \mathrm{~h})$. completely converted into ME, the available acid sites favours the secondary etherification of mono tertiary butyl glycerol ethers to HE.

3.4f Reusability of the catalyst: The catalyst was used repeatedly for etherification of glycerol to investigate its reusability. The used catalyst was recovered from the reaction mixture and washed with methanol, dried and calcined at $773 \mathrm{~K}$ for $2 \mathrm{~h}$. This catalyst is reused for etherification of glycerol to study its performance and the results are shown in figure 9. The catalyst was repeatedly used for 4 reaction cycles. The catalyst activity did not change appreciably with cycles of reuse. The conversion of glycerol and selectivity towards mono- tert-butyl glycerol ether were same for the used catalysts as that of the fresh catalyst. XPS measurements were made on the 5WS catalyst before and after reaction and relevant spectra are shown in figure 10. The XPS spectra of Sn 3d showed two peaks at 486.8 and $495.2 \mathrm{eV}$ corresponding to $\mathrm{Sn} 3 \mathrm{~d}_{5 / 2}$ and Sn $3 d_{3 / 2}$, respectively. These values correspond to that of $\mathrm{Sn}$ (IV) oxide. ${ }^{52}$ The photoelectron peaks of $\mathrm{W} 4 \mathrm{f}_{7 / 2}$

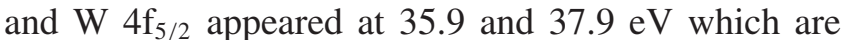
identical to that of $\mathrm{W}$ (VI) oxide. ${ }^{52}$ The XPS results revealed the existence of both $\mathrm{WO}_{3}$ and $\mathrm{SnO}_{2}$ in their simple oxide forms and that there was no formation of any mixed oxides.

3.4g Synthesis of glycerol carbonate: The high active catalyst of the etherification of glycerol prompted to study for the carbonylation of glycerol to yield glycerol carbonate. The carbonylation of glycerol with urea was performed with our previously repeated reaction
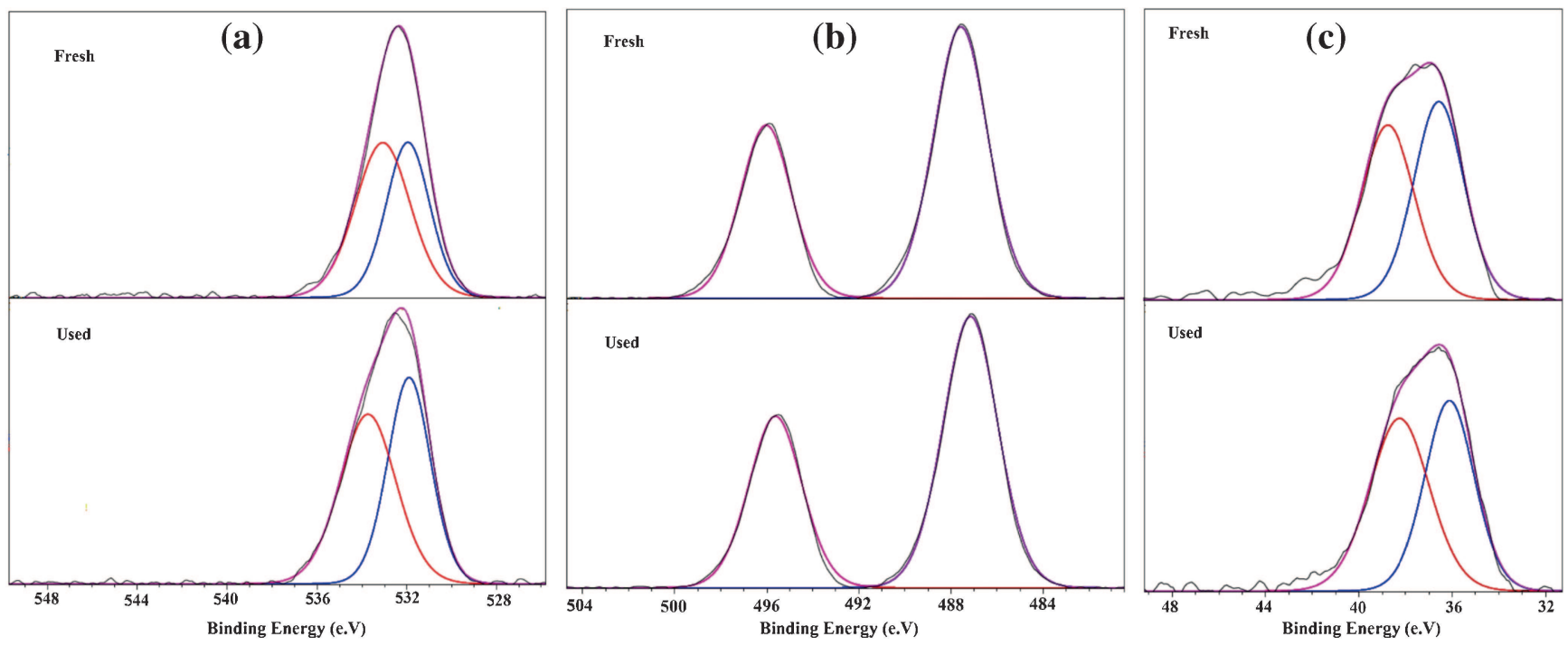

Figure 10. XPS spectrum of the elements present in the fresh and used catalysts (a) O (b) Sn and (c) W. 


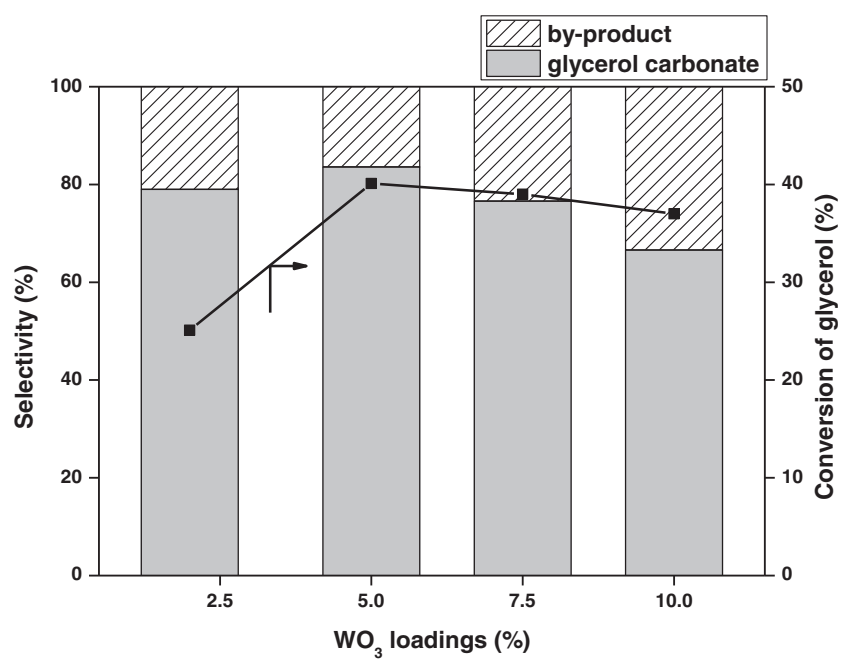

Figure 11. Catalytic performance of $x$ WS catalysts for the synthesis of glycerol carbonate. Reaction conditions: glycerol (2 g), urea (1.3 g), catalyst weight (0.2 g), reaction temperature $(413 \mathrm{~K})$, reaction time $(4 \mathrm{~h})$.

procedure. The activity profiles for the synthesis of glycerol carbonate from glycerol and urea are presented in figure 11. In the glycerol carbonylation with urea, the main product was glycerol carbonate. The other byproducts are 4-(hydroxymethyl) oxazolidine-2-one and (2-oxo-1, 3-dioxolan-4-yl) methyl carbamate. In the present study, only (2-oxo-1, 3-dioxolan-4-yl) methyl carbamate was observed as by-product. In the synthesis of glycerol carbonate also the 5WS catalysts showed better activity. About $40.4 \%$ of glycerol conversion with $85.4 \%$ selectivity towards glycerol carbonate was achieved over this catalyst. These results indicate that the $\mathrm{WO}_{3}$ supported on $\mathrm{SnO}_{2}$ are highly active solid acid catalysts for the conversion of glycerol into value added chemicals such as glycerol ethers and glycerol carbonate.

3.4h Comparison of the catalyst with other reported catalysts: Table 4 presents etherification of glycerol

Table 4. Comparison of glycerol etherification activity of present catalysts with other reported catalysts.

\begin{tabular}{|c|c|c|c|c|}
\hline S. No & Catalysts & Time (min) & Conversion $(\%)$ & Ref \\
\hline 1 & $5 \mathrm{WS}$ & 60 & 84 & [Present work] \\
\hline 2 & SCC-S & 240 & 81.6 & 62 \\
\hline 3 & A-35 & 480 & 86 & 63 \\
\hline 4 & A-15 & 480 & 79 & 63 \\
\hline 5 & $5 \mathrm{WS}^{\mathrm{a}}$ & 240 & 40.4 & [present work] \\
\hline 6 & SnW21 ${ }^{\mathrm{a}}$ & 240 & 52.1 & 64 \\
\hline
\end{tabular}

${ }^{\text {a }}$ These catalysts were used for synthesis of glycerol carbonate with tert-butanol found in the literature compared with results obtained in this work. By analyzing the table, it was possible to confirm that the results obtained using 5WS as a catalyst for etherification of glycerol with tert-butanol were quite satisfactory because the conversion were similar or higher than other catalysts presented in the literature. ${ }^{62,63}$ The use of catalysts such as acid ion exchange resins (A-15 and A35) and sulfated carbon catalysts (SCC-S) showed the reasonable conversion of glycerol and also showed the formation of tert-butyl ethers as by-product at higher temperatures. The best results were obtained with the pure isobutylene but it is very expensive. Additionally, these other catalysts had production costs much higher than present 5WS catalyst prepared from low-cost raw materials.

The present 5WS catalysts was also compared for its carbonylation of glycerol to glycerol carbonate activity with our previous reported tin-tungsten mixed oxide (SnW21) catalyst. ${ }^{64}$ SnW21 catalyst showed about $52.1 \%$ conversion of glycerol whereas the $5 \mathrm{WS}$ catalyst showed $40.4 \%$ under similar conditions. The important thing about present 5WS catalyst is that it showed activity in both carbonylation and etherification of glycerol, whereas SnW21 showed better activity only in carbonylation reaction.

\section{Conclusions}

Tungsten oxide supported on tin oxide catalysts are highly active for the conversion of glycerol into its ethers and glycerol carbonate. The catalytic activity depended on the acidity of the catalysts which in turn is related to the presence of well dispersed amorphous $\mathrm{WO}_{3}$. The nature of $\mathrm{WO}_{3}$ species depended on the amount of $\mathrm{WO}_{3}$ and the catalyst calcination temperature. The catalyst with 5 wt. $\% \mathrm{WO}_{3}$ on $\mathrm{SnO}_{2}$ calcined at $773 \mathrm{~K}$ for $4 \mathrm{~h}$ exhibited maximum activity. The conversion and selectivity during the glycerol etherification also depended on the reaction temperature, catalyst, concentration and molar ratio of reactants and these parameters have been optimized.

\section{Acknowledgements}

MS and GR thank Council of Scientific and Industrial Research (CSIR), India for the financial support in the form of a Senior Research Fellowship. We also thank Ms. Marline Daniel for Raman spectral analysis. NL thanks CSIR for the award of Raman Research Fellowship to carry part of the present work at IRCELYON, France. 


\section{References}

1. Corma A, Sara I and Alexandra V 2007 Chem. Rev. 107 2411

2. Chun-Hui (Clayton) Z, Beltramini J N, Yong-Xian F and Lu(Max) G Q 2008 Chem. Soc. Rev. 37527

3. Behr A, Eilting J, Irawadi K, Leschinski J and Lindner F 2008 Green Chem. 1013

4. Hirai T, Ikenaga N, Miyake T and Suzuki T 2005 Energy Fuels 191761

5. Balaraju M, Rekha V, Sai Prasad P S, Prabhavathi Devi B L A, Prasad R B N and Lingaiah N 2009 Appl. Catal. A: Gen. 35482

6. Climent M J, Corma A, Frutos P D, Sara I, Maria N, Alexandra V and Concepción P 2010 J. Catal. 269 140

7. Katryniok B, Paul S, Capron I, Christine L, BellièreBaca V, Patrick R and Franck D 2010 Green Chem. 12 1922

8. Dam J, Djanashvili K, Kapteijn F and Hanefeld U 2013 ChemCatChem 5497

9. Joel B and François J 2008 Eur. J. Lipid Sci. Technol. 110825

10. Rahmat N, Abdullah A Z and Mohamed A R 2010 Renew. Sust. Energ. Rev. 14987

11. Karinen R S and Krause A O I 2006 Appl. Catal A: Gen. 306128

12. Kovvali A S and Sirkar K K 2002 Ind. Eng. Chem. Res. 412287

13. Parameswaram G, Srinivas M, Hari Babu B, Sai Prasad P S and Lingaiah N 2013 Catal. Sci. Technol. 33242

14. Selva M and Fabris M 2009 Green Chem. 111161

15. Ghandi M, Mostashari A, Karegar M and Barzegar M 2007 J. Am. Oil Chem. Soc. 84681

16. Rokicki G, Rokoczy P, Parzuchowski P and Sobiecki M 2005 Green Chem. 7529

17. Teles J H, Rieber N and Harder W 1994 US Patent 5359094

18. Malyaadri M, Jagadeeswaraiah K, Sai Prasad P S and Lingaiah N 2011 Appl. Catal. A: Gen. 401153

19. Simanjuntak F S H, Kim T K, Lee S D, Ahn B S, Kim H S and Lee H 2011 Appl. Catal. A:Gen. 401 220

20. Takagaki A, Iwatani K, Nishimura S and Ebitani K 2010 Green Chem. 12578

21. Climent M J, Corma A, Frutos P D, Iborra S, Noy M, Velty A and Concepcion P 2010 J. Catal. 269 140

22. Hammond C, Sanchez J A L, Rahim M H A, Dimitratos N, Jenkins R L, Carley A F, He Q, Kiely C J, Knight D W and Hutchings G J 2011 Dalton Trans. 403927

23. Marcos F R, Casilda V C, Banares M A and Fernandez J F 2010 J. Catal. 275288

24. Dibenedetto A, Angelini A, Aresta M, Ethiraj J, Fragale C and Nocito F 2011 Tetrahedron 671308

25. Vieville C, Yoo J W, Pelet S and Mouloungui Z 1998 Catal. Lett. 56245

26. George J, Patel Y, Pillai S M and Munshi P 2009 J. Mol. Catal. A: Chem. 3041

27. Yanlong G, Azzouzi A, Pouilloux Y, François J and Barrault J 2008 Green Chem. 10164

28. González M D, Cesteros Y and Salagre P 2013 Appl. Catal. A: Gen. $\mathbf{4 5 0} 178$
29. Frusteri F, Arena F, Bonuraa G, Cannilla C, Spadaroa L and Di Blasi O 2009 Appl. Catal.A: Gen. 367 77

30. Yuan Z, Xia S, Chen P, Hou Z and Zheng X 2011 Energy Fuels 253186

31. Behr A and Obendorf L 2002 Eng. Life. Sci. 2185

32. Klepacova K, Mravec D, Kaszonyi A and Bajus M 2007 Appl. Catal. A: Gen. 3281

33. Melero J, Vicente A G, Morales G, Paniagua M, Moreno J M, Roldan R, Ezquerro A and Perez C 2008 Appl.Catal A: Gen. 34644

34. Klepacova K, Mravec D, Hajekova E and Bajus M 2003 Pet. Coal 4554

35. Janaun J and Ellis N 2010 J. Appl. Sci. 102633

36. Viswanadham N and Saxena S K 2012 Fuel 105490

37. Yadav G D, Chandan P A and Gopalaswami N 2012 Clean. Techn. Environ. Policy 1485

38. Lupan O, Chow L, Chai G, Schulte A, Park S and Heinrich H 2009 Mater. Sci. Eng. B 157101

39. Okutsu T 2007 J. P. Pat. 039347

40. Yoo J W and Mouloungui Z 2003 Stud. Surf. Sci. Catal. 146757

41. Park J H, Choi J S, Woo S K, Lee S D, Cheong M, Kim H S and Lee H 2012 Appl. Catal. A: Gen. 43335

42. Aresta M, Dibenedetto A, Nocito F and Ferragina C 2009 J. Catal. 268106

43. Climent M J, Corma A, Frutos P D, Iborra S, Noy M, Velty A and Concepcion P 2010 J. Catal. 269140

44. Marcos F R, Casilda V C, Banares M A and Fernandez J F 2010 J. Catal. 275288

45. Ramesh Kumar Ch, Jagadeeswaraiah K, Sai Prasad P S and Lingaiah N 2012 ChemCatChem 41360

46. Hammond C, Sanchez J A L, Rahim M H A, Dimitratos N, Jenkins R L, Carley A F, He Q, Kiely C J, Knight D W and Hutchings G J 2011 Dalton Trans. 40 3927

47. Furuta S, Matsuhashi H and Arata K 2004 Appl. Catal. A: Gen. 269187

48. Maksimov G M, Litvak G S, Budneva A A, Paukshtis E A, Salanov A N and Likholobov V A 2006 Kinet. Catal. 47564

49. Mallesham B, Sudarsanam P, Raju G and Reddy B M 2013 Green Chem. 15478

50. Shoulia B, Dianqinga L, Dongmeia H, Ruixiana L, Aifana C and Liub C C 2010 Sens. Actuators B 150 749

51. Ayyappan S, Subbanna G N and Rao C N R 1995 Chem. Eur. J. 1165

52. Sarkar A, Ghosh S K and Pramanik P 2010 J. Mol. Catal. A: Chem. 32773

53. Loridant S 2002 J. Phys. Chem. B 10613273

54. Abello L, Bochu B, Gaskov A, Koudryavtseva S, Lucazeau G and Roumyantseva M 1998 J. Solid State Chem. 13578

55. Scheithauer M Grasselli R K and Knözinger H 1998 Langmuir 143019

56. Ross-Medgaarden E I and Wachs I E 2007 J. Phys. Chem. C 11115089

57. Loridant S, Feche C, Essayem N and Figueras F 2005 J. Phys. Chem. B 1095631

58. Boulova M and Lucazeau G 2002 J. Solid State Chem. 167425 
59. Kim T, Burrows A, Kiely C J and Wachs I E $2007 \mathrm{~J}$. Catal. 246370

60. Ramu S, Lingaiah N, Prabhavathi Devi B L A, Prasad R B N, Suryanarayana I and Sai Prasad P S 2004 Appl. Catal. A: Gen. 276163

61. Ball P, Fullmann H and Heitz W 1980 Angew. Chem. Int. Ed. Engl. 19718
62. Gonçalves M, Souza V C, Galhardo T S, Mantovani M, Figueiredo F C A, Mandelli D and Carvalho W A 2013 Ind. Eng. Chem. Res. 522832

63. Klepácǒva K, Mravec D and Bajus M 2006 Chem. Pap. 60224

64. Jagadeeswaraiah K, Kumar C R, Prasad P S S, Loridant S and Lingaiah N 2014 Appl. Catal. A: Gen. 469165 